\title{
Democratized Morality. Formal Preliminaries to Contractualist Ethics
}

\author{
Christian J. Feldbacher ${ }^{1,2}$ \\ ${ }^{1}$ Department of Philosophy, University of Innsbruck, Innsbruck, Austria \\ ${ }^{2}$ Philosophy of Science Department, Salzburg, Austria \\ Email: christian.feldbacher@sbg.ac.at
}

Received February $14^{\text {th }}, 2012$; revised March $18^{\text {th }}, 2012$; accepted March $28^{\text {th }}, 2012$

\begin{abstract}
This paper discusses one of the advantages of applying formal methods in ethics. First, an approach from democratic morality - which is a special case of contractualist ethics that brings together theories of legal and moral philosophy - will be adopted, in order to argue for the non-trivial thesis that moral norms are increasingly democratically motivated. To accept this thesis also as a desired way of justifying ethical principles raises some issues, such as the problem of providing adequate principles for moral opinion pooling. Secondly, it is therefore shown how formal criteria of rationality provide at least a partial solution to such problems. In a broad context this results can be seen as formal preliminaries to contractualist ethics.
\end{abstract}

Keywords: Contractualism; Moral Opinion Pooling; Problem of Imperfect Community; Criteria of Rationality; Tolerance

\section{Introduction}

Since the development of deontic systems of logic, formal methods have spread to the field of ethics. This paper discusses an instance of the application of these methods. We are going to discuss in detail one of the advantages of the application of formal methods in the area of legislation. For this purpose, first the so-called democratization of morality thesis - which is seen as a descriptive part of contractualist ethics-will be discussed very shortly and in heuristic and general terms only; the thesis of democratization of morality refers to the fact that in the laws of western societies moral norms are increasingly determined by democratic principles (The Democratization of Morality). Following this general discussion, some formal criteria of rationality will be investigated since their use proves very promising for contractualist ethics (Formal Criteria of Rationality). This section is a little bit technical, but nevertheless the text ahead and behind the formal parts should allow a reader who is not familiar with logical methods to get the main points of the discussion.

Note, that in this paper the terms "morality" and "moral" are used for the predication of specific systems of legal norms and behaviour in accordance with or oriented towards these systems of legal norms; the term "ethical" is solely used for justifications of and investigations in the field of ethics.

\section{The Democratization of Morality}

This section endeavours to show very generally how changes in society, in technology and in economy have given rise to a morality that is more and more democratized. The goal is to provide a very basic outline of arguments with a restriction to paradigmatic examples. The reader may note that a reductionist point of view regarding morality is a very important underlying assumption of our whole argumentation: we are going to investigate morality only in the context of legal norms. So, if, e.g., a legal norm prohibits stem cell research and the legal norm is fully accepted by a person (where acceptance of a norm is expressed by acting in accordance with the norm/law), then we also assume that a prohibition of stem cell research is also the person's moral attitude. But let us begin with the examples now:

Example. Change in European societies: since the foundation of the European Union, nationality has less impact on judiciary systems. The members of different societies perceive this fact in varied ways, since in every country, the media focus on different issues. In Austria, for instance, there was a heated discussion about opening the water market to foreign countries. In this context, the question arose whether Spanish contractors for example would be permitted to buy Austrian water resources. A similar debate regarding land policy took place in Hungary and Poland, while Slovakia discussed similar questions regarding its energy policy. Decreasing the importance of nationality in judiciary systems does not only result in economic effects such as these but also in changes in morality. There has been significant change, for instance, in moral values regarding the keeping of animals. It is evident that these changes are due to democratic decisions, which illustrates how moral systems are increasingly defined by the system of democracy they originate from.

Example. Changes in technology that have led to new moral systems can be found especially in the fields of medical technology and medical ethics. The extensive discussions on the subject of embryonic stem cell research for example, call for adjustments in moral systems. Taking the form of democratic decisions, they have led to the following results:

- Germany: production forbidden; research allowed;

- England: production allowed; research allowed;

- Italy: production forbidden; research forbidden;

In Formal Criteria of Rationality this example is discussed in more detail. 


\section{J. FELDBACHER}

Example. The current changes in the economy, caused by the penultimate year's financial crisis, and the demand for new norms in the financial sector it has evoked, serve as a further example for the increased democratization of morality. The demands include, for instance, the establishment of national and supranational boards of control for banks and national budgets. From a historical perspective, these demands represent changes in liberalistic programmes by means of democratic decisions: an increasing amount of the population shares the opinion that at least some moral norms are necessary in order to regulate the market adequately.

These examples have two common grounds: firstly, they are directly concerned with debates about moral norms, such as norms in animal ethics, medical ethics and business ethics. Secondly, the moral evaluation of these changes and the enforcement of new moral norms was not determined by an authority, but by democratic decisions. The norms were not defined by a patron, a church authority or a lobbyist, but by a democratically elected cabinet that was chosen to formulate a democratized morality. This argument may be seen as trivial according the following line of reasoning: 1) Those who dominate a society determine its moral system; 2) Before they became democratic, western societies were dominated by authorities; 3) Hence, before democracy, the societies' moral system was determined by authorities; 4) Since they became democratic, all members of the societies have been democratically determining their moral systems. But this argument appears to be semantically weak, since the moral systems of western societies were for a long time strongly influenced by authorities (e.g. by the churches) and since the new way of enforcing and handling morality - we will call this way here "democratization of morality"- does not coincide temporally with the democratization of societies (vs.1). In support of our claim we refer to the empirical fact that the number of popular votes and referenda on the subject of moral issues increased significantly in western democratic societies.

It is one thing to argue for the thesis of democratization of morality in some societies' legal systems (descriptive), and it is another thing to argue for an acceptance of this thesis as a normative ideal. Both lines of argumentation have in common that they have to examine or investigate methods for moral opinion pooling. The descriptive part is mostly dealt with empirical studies of cases as, e.g., we have given here. The normative part is investigated within contractualist ethics, claiming that in some more or less strict sense all that is to say about moral principles for societies is to say something about the moral attitudes of the societies' members. In the following section we are mainly concerned with methods of contractualist ethics for aggregating individual moral attitudes.

Literature. Here the expression "democratized morality" is used synonymous to "democratic morality" which is descriptive and comparable to the use of the expressions "Christian morality", "morality of the Greeks" etc. (cf. Gert, 2009). Information about stem cell policy in European countries used for our second example is available at: http://www.eurostemmcell.org/ (July, 2011). A popular discussion of ethics codes in economy is given in (Berman, 2005). Some statistics about referenda on moral issues in support of the thesis of democratization of morality is to be found in (Qvortrup, 2002).

\section{Formal Criteria of Rationality}

In the preceding section of this paper it was argued in a very heuristic way and at a very general level that the setting up of new moral values by means of democratic procedures constitutes a relatively recent way of accepting and enforcing moral systems. This process of acceptance stands in opposition to authoritative procedures.

Once the democratization of morality has been agreed on, issues arise concerning the democratic procedures for aggregating the single acceptances of moral norms. Also rules have to be set up for the handling of different opinions regarding moral norms, just like the majority rule which is used in the case of public elections or the unanimity rule which is used in the case of specific jury decisions. One such rule or principle was introduced by the Austrian mathematician Karl Menger. His proposal, which is applied in formal philosophy, offers a promising direction towards a solution to the problem of aggregating single moral attitudes in an adequate way. However, before we go into more detail, the context of discovery of Menger's principle shall be explained sketchily here.

In 1934 at a colloquium at the University of Vienna, Menger presented a mathematical theorem intended for an application in the field of ethics. This theorem, as well as another highly interesting one, was transposed into a more modern frame by Anne Siegetsleitner and Hannes Leitgeb in 2010. The following is a selection of insights this principle yields: many problems in ethics arise out of sets of at least two coexisting, intuitively acceptable but incompatible norms. Thus, for example, from an intuitive point of view, some people hold that embryonic stem cell research is morally permissible, while others of an equally intuitive stance are convinced that it is morally forbidden. There are at least two possible ways for solving this issue, one being an orthodox and another being an unorthodox solution. An orthodox solution to the problem would be to undertake to find two separate justifications for each proposed (but conflicting) norm. Then one tries to derive some counterintuitive consequences of at least one of the justifications where one may be gifted by the fact that exactly one of the justifications leads to counterintuitive principles. In this case it is easy to decide which norm one should accept since she only has to choose the norm that has the deepest structure in terms of intuitive acceptable justifications.

Apart from this orthodox and common approach, there is an unorthodox one, which seems to be much more applicable and which was proposed in a technical investigation first by Menger. Instead of choosing norms by their deepest intuitive and overall acceptable structure of justification, i.e., instead of choosing only those principles that are acceptable to a whole group for a group's moral system, Menger proposes to investigate the moral attitudes of the group's members and to try to find ways for partitioning the group in such a way that only non-conflicting members are in contact. So he thinks that one should not try to find an overall and per se acceptable system of moral norms, but one should find possibilities of restructuring a group in such a way that people with coincident moral opinions act together and people with varying moral opinions stay untouched in situations they disagree.

We shall go into more detail here and therefore introduce some technical vocabulary (explanations of the definitions and theorems are offered below).

Definition 1. $\langle W, N,[]\rangle$ is a Menger*-model of language $L$ iff it holds that:

1) $W$ is a non-empty set of sets of formulas of $L$, and:

2) $N$ is a mapping from $W$ into $\wp(\wp(W))-\{\}$ and: 


\section{J. FELDBACHER}

3) [ ] is a mapping from the set of formulas of L into $\wp(W)$ that fulfils the following conditions: and:

a) For all formulas $A$ of $L$ it holds that: $[\sim A]=W-[A]$

b) For all formulas $A$ and $B$ of $L$ it holds that: $[A \& B]=[A] \cap[B]$ and:

c) For all formulas $A$ of $L$ and for all $w \in W$ it holds that: $w \in[O A]$ if for all $X \in N(w)$ it holds that $X \subseteq[A]$ and:

d) For all formulas $A$ of $L$ it holds that: $[P A]=[\sim O \sim A]$.

Commentary. $L$ is a language containing an operation (and closed under the operations) for negation $(\sim)$, conjunction $(\&)$, obligation $(O)$ and permission $(P)$. $W$ represents a set of possible worlds; $N$ represents those moral systems that are accepted by the population. This acceptance is technically expressed by relativization of $N$ to the set of possible worlds $W$; it is intended to map each person to a possible world (the person's point of view) so that every person is mapped via $N$ to those possible worlds that are seen as ideal from the concerned person's point of view. NB: if, e.g. $w_{1}$ reflects a person's $P_{1}$ point of view and if $N\left(w_{1}\right)=\left\{\left\{w_{2}\right\},\left\{w_{2}, w_{3}\right\}\right\}$, then person $P_{1}$ accepts as moral system (regarding a specific norm that is valid in $w_{2}, w_{3}$ and perhaps in some more possible worlds) exactly the moral system $N\left(w_{1}\right)$. Norms are seen as sets of possible worlds-those possible worlds in which the norm under consideration is valid and systems of norms are seen to be sets of norms. [ ] represents a mapping of formulas of $L$ into the set of possible worlds so that each formula is mapped to those worlds in which it is valid. The usual rules of deontic logic apply with respect to [ ], inasmuch as no norm is valid and invalid in one and the same possible world etc. Furthermore, illustrated by an example, the following holds: if $q$ represents "A specific team carries out research with stem cells in Germany", and if $w$ is the set of those formulas that are true and valid in our world, and if there really is a specific team carrying out research with stem cells in Germany, then $w \in[q]$. Of course $w$ cannot be seen as to be ideal in general, because it is not, for instance, ideal from the Pope's point of view $w_{P}:\{w\} \notin N\left(w_{P}\right)$.

In accordance with usual semantics one can define deontic validity as follows:

Definition 2. A formula $A$ of the language $L$ is deontic valid iff for all Menger*-models $M=\langle W, N,[]\rangle$ of $L$ it holds: $[A]=$ $W$.

It can be shown that the deontic system $D$ is an adequate calculus with respect to the given semantics.

Theorem 1. (cf. Leitgeb in Siegetsleitner \& Leitgeb, 2010: p. 211). A formula $A$ of $L$ is deontically valid iff $A$ is derivable in the system $D$ (whereas the axioms of the system are formulated in $L$ ).

We will not make use of this result, because the interesting question, namely how to create optimal democratic decisions regarding moral systems, is much more easier dealt with in the given semantics than in an expansion of the system $D^{1}$.

Different people accept different systems of norms, however, not all modes of accepting norms seem to be of equal rationality. Menger proved that only modes of acceptance that are - as defined below-fully rounded are rational:

Definition 3. (cf. Siegetsleitner \& Leitgeb, 2010: p. 213). A set of moral systems $N$ is fully rounded iff for every person,

${ }^{1}$ For example, the principle of intermediacy, formulated in Definition 3, is only expressible in an expansion of $D$ with multiple modal operators: $\left(\mathrm{O}_{1} \mathrm{~A}\right.$ $\left.\& \mathrm{O}_{3} \mathrm{C} \&(\mathrm{C} \rightarrow(\mathrm{B} \rightarrow \mathrm{A}))\right) \rightarrow \mathrm{O}_{2} \mathrm{~B}$, where as bridge principle between the modalities it would be assumed that $\mathrm{O}_{3} \mathrm{~A} \rightarrow \mathrm{O}_{2} \mathrm{~A}$ and $\mathrm{O}_{2} \mathrm{~A} \rightarrow \mathrm{O}_{1} \mathrm{~A}$. assigned to a possible world $\mathrm{w}$, it holds that:

- Principle of Intermediacy. A person who accepts two systems of norms, also accepts a system included between them. Technically: if $X \in N(w)$ and $Z \in N(w)$ and $X \subseteq Y \subseteq Z$, then $Y \in N(w)$.

- Restricted Principle of Conjunction. A person who accepts two systems of norms, also accepts a system of norms restricted by combination in case that the norms are noncategorial. Technically: if $X \in N(w)$ and $Y \in N(w)$ and $|X \cap Y|>$ 1 , then $X \cap Y \in N(w)$.

- Principle of Adjunction. A person who accepts two systems of norms, also accepts system of norms expanded by combination. Technically: if $X \in N(w)$ and $Y \in N(w)$, then $X \cup Y$ $\in N(w)$.

Menger showed that these three principles are criteria of rationality, by proving the following theorem which he called "a sentence on finite sets with application to formal ethics":

Theorem 2. (cf. Menger, 1998). A system of systems of norms $N$ is fully rounded iff for every person assigned to a possible world $w$ it holds: the, with respect to $w$, accepted set of systems of norms $N(w)$ contains only ethical norms (permissions, restrictions, oughts, etc.).

This theorem shows that if a person accepts systems of norms according to the criteria given above, only the classical types of moral norms are accepted.

As we are now finished with the introduction of our technical vocabulary, one may ask for what purpose we are armed in such a strong way. In particular one may ask why these criteria of rationality should be so promising in the debate around democratized morality? The answer is simple: there is an issue with moral opinion pooling in democratized morality, which Nelson Goodman called in a much broader context "the imperfect community problem". The problem of imperfect community is that although all members of a community resp. a group may accept pairwise a moral system of norms, there nevertheless may be no moral system that is acceptable for the whole group. Therefore, despite the fact that bilateral debates are successful within the group, there may be no result that is satisfactory to the group altogether. Let us illustrate this problem by an exam- ple: let $w_{1}$ be the ideal possible world from person $P_{1}$ 's point of view, $w_{2}$ the ideal possible world for person $P_{2}$ and $w_{3}$ the ideal possible world for person $P_{3}$. Furthermore, let these persons accept the following moral systems:

- $N\left(w_{1}\right)=\left\{\left\{w_{5}\right\},\left\{w_{6}\right\},\left\{w_{5}, w_{7}\right\},\left\{w_{6}, w_{7}\right\}\right\}$

- $N\left(w_{2}\right)=\left\{\left\{w_{5}\right\},\left\{w_{7}\right\},\left\{w_{5}, w_{7}\right\}\right\}$

- $N\left(w_{3}\right)=\left\{\left\{w_{6}\right\},\left\{w_{7}\right\},\left\{w_{6}, w_{7}\right\}\right\}$

Furthermore let us assume the following model: $\left\{w_{5}\right\} \subseteq[p]$, $\left\{w_{7}\right\} \subseteq[q]$ and $\left\{w_{6}\right\} \subseteq[r]$ with the following representations:

- $\quad$ : " $P$ imports embryonic stem cells (st)".

- $q$ : " $P$ does research with $s t$ ".

- $r$ : "P produces $s t$ ".

So $P_{1}$ accepts the permission of import of $s t$ as a moral system, the permission of production of st as a moral system, the permission of import of and research with st as a moral system, the permission of production of and research with st as a moral system, but no moral system, for example, that permits import of, production of and research with st jointly. $P_{2}$ accepts import of st only, research with st only and both: import of and research with st, while $P_{3}$ accepts production of st only, research with st only and both: production of and research with st, but no import. $P_{2}$ is obviously the legal person's position in Germany. $P_{1}$ and $P_{3}$ are fictitious, where $P_{3}$ seems to be a justifiable posi- 
tion. $P_{3}$, e.g., could represent a legal person that may argue for the permission of producing st, although she thinks that importing st should be forbidden, because she seeks to prevent the economization of st production.

The problem of the imperfect community is now made evident by this example. Each pair of persons $-P_{1}$ and $P_{2}, P_{2}$ and $P_{3}, P_{1}$ and $P_{3}$-accepts a common system of norms, namely:

- $P_{1}$ and $P_{2}$ agree: $N\left(w_{1}\right) \cap N\left(w_{2}\right)=\left\{\left\{w_{5}\right\}\right\}$

- $P_{2}$ and $P_{3}$ agree: $N\left(w_{2}\right) \cap N\left(w_{3}\right)=\left\{\left\{w_{7}\right\}\right\}$

- $P_{3}$ and $P_{1}$ agree: $N\left(w_{3}\right) \cap N\left(w_{1}\right)=\left\{\left\{w_{6}\right\}\right\}$

But what causes the problem at hand is that the whole group $P_{1}-P_{3}$ doesn't accept a single system of norms. $P_{1}, P_{2}$ and $P_{3}$ do not agree in any moral system of norms: $N\left(w_{1}\right) \cap N\left(w_{2}\right) \cap N\left(w_{3}\right)$ $=\{\}$. Therefore, although the bilateral discussions were successful, the group as a whole is not. But who is to take the blame for this? As we can see, according to the criteria presented above, $P_{2}$ 's and $P_{3}$ 's acceptance of their norms is rational, that of $P_{1}$ is not. So it is clear that $P_{1}$, although she is rather tolerant, is one way or another not acting on rational grounds - why would one accept import of, production of and research with st but reject it as a whole and as a single norm? With the help of the following theorem, Leitgeb and Siegetsleitner have shown that it is always the irrational members of a society who are the culprits:

Theorem 3. (cf. Leitgeb in Siegetsleitner \& Leitgeb, 2010: p. 215). For all Menger*-models $M=\langle W, N,[]\rangle$ and all groups $W^{\prime} \subseteq W$ it holds that if $N$ is fully rounded, then:

- If each member of W' agrees with the others in at least one moral system (that is: for every $w \in W^{\prime}, w^{\prime} \in W^{\prime}$ it holds that: $\left.N(w) \cap N\left(w^{\prime}\right) \neq\{\}\right)$, then it holds that:

- There is a moral system acceptable for the group altogether (that is: there is $a X \subseteq W$ such that $X \in \cap w \in W^{\prime} N(w)$ ).

According to this theorem, the problem of the imperfect community is avoidable, provided that all members of the community have rational attitudes towards norms.

The key idea of this theorem would be that if bilateral talks are successful and all members of a group are rational, then the group as a whole will be successful. As we have seen, $P_{1}$ behaves in an irrational manner and is therefore the person responsible for the group's failure to find a common system of norms. How would a rationalized version of $P_{1}$, called $P_{1}$, and represented below, affect the group's overall success in agreeing on a common system?

- $N\left(w_{1}\right)=\left\{\left\{w_{5}\right\},\left\{w_{6}\right\},\left\{w_{5}, w_{6}\right\},\left\{w_{5}, w_{7}\right\},\left\{w_{6}, w_{7}\right\},\left\{w_{5}, w_{6}, w_{7}\right\}\right\}$

$P_{1}$, satisfies all criteria of rationality and obviously represents England's position in this matter: import, production and research of st is allowed-in a single norm, in combination and generally as a whole. So what is the common system of norms regarding st? England, Germany and the fictitious position agree on permitting research with $s t$, which means that on the subject of st they form a community of interest: $N\left(w_{1}\right) \cap N\left(w_{2}\right)$ $\cap N\left(w_{3}\right)=\left\{w_{7}\right\}$. So they can agree on a common policy on research with st, but have to handle production and import separately.

What one can learn from this problem and the given solution is the circumstance that a moral opinion pooling method should presuppose these rationality constraints in order to be effective for contractualist ethics. So these constraints seem to be a necessary (but of course no sufficient) basis for contractualist ethics.

The criteria of rationality which are given here allow one to show another very interesting result on tolerance:
Corollary. (By us). For all Menger*-models $M_{1}=\left\langle W, N_{1},[]\right\rangle$ and $M_{2}=\left\langle W, N_{2},[]\right\rangle$ and all groups $W^{\prime} \subseteq W$ it holds that if $N_{1}$ and $\mathrm{N}_{2}$ are fully rounded, and:

- If each member of $W^{\prime}$ agrees with the others in at least one moral system - that is: for every $w \in W^{\prime}, w^{\prime} \in W^{\prime}$ it holds that: $N_{1}(w) \cap N_{1}\left(w^{\prime}\right) \neq\{\}$ and $N_{2}(w) \cap N_{2}\left(w^{\prime}\right) \neq\{\}$, and:

- $N_{2}$ is more tolerant than $N_{1}$-that is: for every $w \in W^{\prime}, w^{\prime}$ $\in W^{\prime}$ it holds that: $N_{1}(w) \cap N_{1}\left(w^{\prime}\right) \subseteq N_{2}(w) \cap N_{2}\left(w^{\prime}\right)$,

Then a fully acceptable moral system based on $N_{2}$ is also at least as tolerant as a fully acceptable moral system based on $N_{1}-$ that is: there is $a X \subseteq W$ and $a Y \subseteq W$ so that $X \in \cap W \in W^{\prime}$ $N_{1}(w)$ and $Y \in \cap w \in W^{\prime} N_{2}(w)$ and $X \subseteq Y$.

According to this corollary, a group's whole system of norms is the more tolerant, the more tolerant the bilateral talks within the group are, whereas it holds that a person, assigned to the point of view $w$, is more tolerant in accepting a system of norms than another person $\left(w_{0}\right)$, if all systems of norms accepted by $w_{0}$ are also accepted systems of norms of $w$. The modified key idea would be: If every person undertakes to be successful, rational and tolerant in bilateral discussions, than the group's system of moral norms will also be successful and tolerant.

Literature. For Menger's theorem, see (Menger, 1998: p. 293f). For Goodman's presentation of the imperfect community problem, see (Goodman, 1951: p. 125). For a discussion of the criteria of rationality by Siegetsleitner and Leitgeb, see (Siegetsleitner \& Leitgeb, 2010: p. 211ff). For a general discussion of opinion pooling methods cf. (List \& Pettit, 2002). A general overview on Menger's ethical theory is given in (Leonard, 2010).

\section{Conclusion}

In this paper we have established a heuristic and general line of argumentation in favour of what is termed the thesis of democratized morality which states that moral systems are increasingly enforced by democratic than by authorities' decisions. One of the issues that arise when moral systems are accepted by means of democratic processes (contractualist ethics) is the imperfect community problem. This problem indicates the fact that although all pairs of people within a group may find a system of norms acceptable to them, there may be no moral system that is acceptable to the whole group. We have presented here a solution to this problem of moral opinion pooling that is provided by Siegetsleitner and Leitgeb in their discussion of criteria for rationality in moral opinion formation and extended their result by showing that their solution meets also other intuitions on moral opinion formation, namely intuittions on tolerance: the more people are tolerant in bilateral talks, the more the whole system of norms is tolerant. This is the reason why we think that Siegetsleitner's and Leitgeb's approach in the spirit of Menger could serve as a viable solution for problems in the democratization of morality and hence may serve as formal preliminaries to contractualist ethics.

\section{Acknowledgements}

This research was supported by the Philosophy of Science Department Salzburg, Austria.

\section{REFERENCES}

Berman, D. K. (2005). Does wall street finally need an ethics code? The 


\section{J. FELDBACHER}

Wall Street Journal, C1.

Gert, B. (2009). The definition of morality. In E. N. Zalta (Ed.), The stanford encyclopedia of philosophy. Stanford: The Metaphysics Research Lab.

Goodman, N. (1951). The structure of appearance. Harvard: Harvard University Press.

Leonard, R. (2010). Von Neumann, Morgenstern, and the creation of game theory. Cambridge: Cambridge University Press.

List, C., \& Pettit, P. (2002). Aggregating sets of judgements: An impossibility result. Economics and Philosophy, 18, 89-110.

Menger, K. (1998). Ergebnisse eines Mathematischen Kolloquiums. In E. Dierker, \& K. Sigmund (Eds.), Wien: Springer.

Qvortrup, M. (2002). A comparative study of referendums: Government by the people. Manchester: Manchester University Press.

Siegetsleitner, A., \& Leitgeb, H. (2010). Mengers Logik für Ethik und Moral: Nichts von Sollen, nichts von Güte, nichts von Sinnlosigkeit. In A. Siegetsleitner (Ed.), Logischer Empirismus, werte und moral. Eine neubewertung (pp. 199-218.) Wien: Springer. 